\title{
VÍCTIMAS DE TRATA DE SERES HUMANOS, MADRES DE SERES HUMANOS: PROTEGIENDO DERECHOS
}

\section{VICTIMS OF TRAFFICKING IN HUMAN BEINGS, MOTHERS OF HUMAN BEINGS: PROTECTING RIGHTS}

Tania García Sedano. Universidad Carlos III y Universidad Pontificia de Comillas España

tgsedano@der-pu.uczm.es

Resumen España es un país de tránsito y destino de víctimas de trata de seres humanos. El principal reto al que se enfrenta España, muy especialmente dada su condición de única frontera terrestre europea con el continente africano, es sin duda la importancia de identificación de las víctimas de trata. La ausencia de identificación, rápida y precisa, de las víctimas de trata hace que sus derechos sean puramente teóricos e ilusorios. Circunstancia que se incrementa potencialmente cuando se trata de los derechos de mujeres madres víctimas de trata y de sus hijos. Ese contexto plantea numerosos desafíos en torno a la adecuación del sistema de protección a la infancia y de protección a las víctimas de trata. Pretender la protección a partir de la aplicación de normas generales: infancia y extranjería, no constituye, como se está constatando, una solución adecuada para la flagrante violación de derechos humanos a la que nos enfrentamos. Este artículo tiene como objetivo el aproximarnos a la realidad de víctimas de trata de seres humanos que son madres así como a la tutela y protección de sus derechos y vínculos.

Palabras clave: Trata de seres humanos, víctimas de trata, madres, hijos, declaración de riesgo, situación de desamparo

Abstract: Spain is a transit and destination country for victims of trafficking in human beings. The main challenge facing Spain, especially given its status as the only European land border with the African continent, is undoubtedly the importance of identifying victims of trafficking. The lack of identification, quickly and accurately, of victims of trafficking in minors, makes their rights purely theoretical and illusory. This context raises numerous challenges regarding the adequacy of the child protection system and the protection of victims of trafficking. Pretending protection based on the application of general norms: children and foreigners, does not constitute, as is being verified, an adequate solution for the flagrant violation of human rights that we face.

Key words: Traffiking in human beings, victims, mothers, children, declaration of risk, situation of helplessness 


\section{Introducción}

Por lo que se refiere a la metodología empleada es la propia de las ciencias jurídicas y en concreto, en el derecho administrativo y el Derecho Internacional de los Derechos Humanos. Desde esa perspectiva no sólo se ha acudido a normas Convencionales sino que por un lado, se ha acudido a la interpretación que de los mismos han hecho el Tribunal Europeo de Derechos Humanos, el Tribunal Supremo y otros tribunales. Por otro, se han estudiado las Comunicaciones e Informes aprobados por los distintos Consejos creados al amparo de la Organización de las Naciones Unidas y de la Unión Europea.

A lo largo del presente trabajo se ha empleado, así mismo un método jurídicopropositiva, en el que, partiendo de los fallos o lagunas en la regulación vigente se realizan propuestas de lege ferenda.

El objetivo fundamental del presente trabajo es ofrecer una mirada a la realidad de mujeres que siendo víctimas de un delito muy grave, como es la trata, son madres. La intersección de ambas realidades merece una profunda atención y una especial aproximación desde la protección a todos los derechos presentes que se despoje de prejuicios y estereotipos ${ }^{1}$.

\section{El delito de trata de seres humanos}

El delito de trata de seres humanos es un delito grave ${ }^{2}$ pero no sólo eso, es además una flagrante violación de derechos humanos.

El Protocolo para prevenir, reprimir y sancionar la trata de personas, especialmente mujeres y niños ${ }^{3}$, que, como ya se ha señalado, complementa la Convención de las Naciones Unidas contra la Delincuencia Organizada Transnacional 4 cuyo artículo 3 establece que: "Por "trata de personas" se entenderá la captación, el transporte, el traslado, la acogida o la recepción de personas, recurriendo a la amenaza o al uso de la fuerza u otras formas de coacción, al rapto, al fraude, al engaño, al abuso de poder o de una situación de vulnerabilidad o a la concesión o recepción de pagos o

\footnotetext{
${ }^{1}$ Chimananda Ngozi, (Ngozi, 2018) lo refleja magistralmente: "Cuando cumplí ocho años, un nuevo chico llegó a mi casa. Se llamaba Fide. Lo único que mi madre nos contó de él fue que su familia era muy pobre. Mi madre les mandaba ñame y arroz y ropa que ya no nos poníamos. (...) Entonces, un sábado, fuimos de visita a su pueblo y su madre nos enseñó una preciosa cesta de rafia estampada que había confeccionado el hermano de Fide. Me quedé impresionada. No se me había ocurrido que alguien de su familia supiera hacer algo. Lo único que oía de ellos era lo pobres que eran, de modo que me resultaba imposible verlos como algo más que pobres. Su pobreza era mi único relato sobre ellos". Hemos elegido a esta autora por ser mujer y nigeriana características que son predicables de un elevado porcentaje de víctimas de trata de seres humanos en España. El propósito es coadyuvar a desmontar los estereotipos que invisibilizan a las mujeres víctimas de trata nigerianas.

${ }^{2}$ Artículo 13 del Código Penal.

3Publicado en Diario Oficial de la Unión Europea. No 262 de fecha 22 de Septiembre de 2006 y Boletín Oficial del Estado de fecha 11 de Diciembre de 2003.

4Publicado en Boletín Oficial del Estado de fecha 29 de Septiembre de 2003.
} 
beneficios para obtener el consentimiento de una persona que tenga autoridad sobre otra, con fines de explotación.

Esa explotación incluirá, como mínimo, la explotación de la prostitución ajena u otras formas de explotación sexual, los trabajos o servicios forzados, la esclavitud o las prácticas análogas a la esclavitud, la servidumbre o la extracción de órganos 5 ".

La Relatora Especial sobre la Trata de Personas, especialmente Mujeres y Niños, Ngozi ${ }^{6}$, en su primer Informe la definió como una negación de prácticamente todos los derechos humanos: "el derecho a la libertad, la integridad y la seguridad de la persona; el derecho de no ser sometido a torturas ni a otros tratos crueles, inhumanos o degradantes; el derecho a la libre circulación; el derecho a fundar un hogar y una familia; el derecho al mayor nivel posible de salud y el derecho a la educación".

\section{La identificación de las víctimas}

La identificación de las víctimas de trata de seres humanos es una condición indispensable para su protección ${ }^{7}$ y afecta de manera directa al agravamiento de las condiciones de especial vulnerabilidad en las que se encuentran estas personas ${ }^{8}$. De no producirse nos encontramos, por un lado ante un fracaso estatal y un incumplimiento de obligaciones internacionales ${ }^{9}$. Por otro, ante una desprotección de las víctimas.

\footnotetext{
5 Tribunal Europeo de Derechos Humanos. Asunto Rantsev vs Chipre y Rusia, sentencia de fecha 7 de enero de 2010. Párrafo 281. La trata de seres humanos, tal y como se define en el Protocolo de las Naciones Unidas contra la Trata y en el Convenio del Consejo de Europa sobre lucha contra la trata de seres humanos, se halla prohibida en el artículo 4 del Convenio Europeo para la protección de los Derechos Humanos y de las Libertades fundamentales, sin que sea necesario que sea calificada como esclavitud, servidumbre o trabajo forzoso "La trata de seres humanos, por su propia naturaleza y finalidad de explotación, se basa en el ejercicio de los poderes atribuidos al derecho de propiedad. Trata a los seres humanos como mercancías que se compran y se venden y son sometidos a trabajos forzosos, a menudo por escaso o ningún pago, por lo general en la industria del sexo, pero también en otras. Esto implica una estrecha vigilancia de las actividades de las víctimas, cuyos movimientos se limitan a menudo. Conlleva el uso de la violencia y las amenazas contra las víctimas, que viven y trabajan en condiciones míseras".
}

${ }^{6} \mathrm{NGOZI}$ EZEILO, J. Informe de la Relatora Especial sobre la trata de personas, especialmente mujeres y niños, Promoción y protección de todos los derechos humanos, civiles, políticos, económicos, sociales y culturales, incluido el derecho al desarrollo. Consejo de derechos humanos. Décimo período de sesiones. Tema 3 de la agenda.

7 PARLAMENTO EUROPEO. Resolución del Parlamento Europeo, de 5 de julio de 2016, sobre la lucha contra el tráfico de seres humanos en las relaciones exteriores de la UE. La lucha contra la trata de seres humanos en las relaciones exteriores de la UE. Documento n 2015/2340(INI). Derechos de las víctimas, incluido el derecho de recurso. Párrafo 55.

${ }^{8}$ DEFENSOR DEL PUEBLO. Informe. Madrid. 2015. p. 244.

9 Tribunal Europeo de Derechos Humanos, Rantsev vs Chipre y Rusia, Sentencia de fecha 10 de mayo de 2010. 
Según Frontex la aparición de muchos de los indicadores de trata se hace efectiva una vez dentro del territorio de la Unión ${ }^{10}$ pues no suele ser si no hasta el momento que las víctimas han comenzado a sufrir la explotación.

Tanto el Convenio del Consejo de Europa como la Directiva ${ }^{11}$ inciden en que para una adecuada detección e identificación de las víctimas se hace preciso garantizar una apropiada formación de los agentes intervinientes así como establecer procedimientos $^{12}$ garantistas conformes a una perspectiva tanto de derechos humanos como de género ${ }^{13}$.

${ }^{10}$ FRONTEX. Situational Overview on Trafficking in Human Beings. Varsovia, 2011.p. 6. FRONTEX. Annual Risk Analysis. Varsovia, 2012. p. 32.

${ }^{11}$ El Artículo 10 párrafo 1 del Convenio de Varsovia establece que las partes deben dotar a las autoridades competentes de "personas formadas y cualificadas en la prevención y la lucha contra la trata de seres humanos y en la identificación y la ayuda de las víctimas". El Artículo 18 párrafo 3 de la Directiva 2011/36 / UE establece que: "Los Estados miembros promoverán la formación periódica de los funcionarios que puedan a entrar en contacto con las víctimas o posibles víctimas de la trata de seres humanos, incluida la policía de primera línea oficiales, objeto de que puedan identificar y tratar a las víctimas y posibles víctimas de la trata de seres humanos". Por otra parte, el artículo 9 párrafo 3 de la Directiva exige a los Estados miembros a adoptar las medidas necesarias para garantizar que las personas, unidades o servicios responsables de investigar o enjuiciar los delitos contemplados en los artículos 2 y 3 reciben una formación adecuada. Desde las Instituciones Comunitarias la postura es unánime, en ese sentido se pronuncia la COMISIÓN EUROPEA. Resolución sobre la Comunicación de la Comisión al Consejo y al Parlamento sobre la trata de mujeres con fines de explotación sexual. 1998. Documento nº COM (96) 0567-C4-0638/96. Apartado 31.y PARLAMENTO EUROPEO. Resolución del Parlamento Europeo, de 5 de julio de 2016, sobre la lucha contra el tráfico de seres humanos en las relaciones exteriores de la UE. La lucha contra la trata de seres humanos en las relaciones exteriores de la UE. Documento: 2015/2340(INI). Dimensión económica de la trata de seres humanos. Párrafo 20. Por su parte, la Relatora Especial sobre las formas contemporáneas de la esclavitud, incluidas sus causas y consecuencias subraya la necesidad de formación de los agentes para terminar con la realidad que nos ocupa. SHAHINIAN, G. Informe temático sobre las dificultades y enseñanzas de la lucha contra las formas contemporáneas de la esclavitud.2013. Documento n० A/HRC/24/43. Párrafo 63. En idéntico sentido, WARZAZI, S. Informe del Grupo de Trabajo sobre las Formas Contemporáneas de la Esclavitud acerca de su $22^{\circ}$ período de sesiones. Documento E/CN.4/Sub.2/1997/13. Párrafo 37.

${ }^{12}$ Entendemos que el abordaje de esta cuestión debe realizarse desde una perspectiva de derechos humanos. Por ello, no compartimos el criterio de GUILLÉN ÁLVAREZ, I. "Aproximación y análisis jurídico a los fenómenos del tráfico y trata de seres humanos" en Diario La Ley No 8585, 2015. p. 4 Y 5. El autor propone que para la detección de víctimas dentro del territorio nacional se practiquen: "controles y requerimientos de identificación de extranjeros que las Fuerzas y Cuerpos de Seguridad realizan en lugares de confluencia de extranjeros, zonas de tránsito, hospedajes, establecimientos públicos, etc (...)". No podemos más que disentir de estas propuestas, no consideramos que sea el medio idóneo de detección e identificación de víctimas de trata. Así, por un lado no podemos obviar que nuestro país ha sido condenado por el COMITÉ DE NACIONES UNIDAS CONTRA LA DISCRIMINACIÓN RACIAL Comunicación 1493/2006, de fecha 17 de agosto de 2006, por considerar ilegales los controles de identidad basados en rasgos raciales. Esta decisión expuso que: "cuando las autoridades efectúan dichos controles, las meras características físicas o étnicas de las personas objeto de los mismos, no deben ser tomadas en consideración como indicios de su posible situación ilegal en el país. Tampoco deben efectuarse de manera tal que sólo las personas con determinados rasgos físicos o étnicos sean señaladas. Lo contrario no sólo afectaría negativamente la dignidad de las personas afectadas, sino que además contribuiría a la propagación de actitudes xenófobas entre la población en general y sería contradictorio con una política efectiva de lucha contra la discriminación racial". Por otro lado, MUTUMA, R. Informe del Relator Especial sobre las formas contemporáneas de racismo, discriminación racial, xenofobia y formas conexas de 
Naciones Unidas al interpretar la Directiva ${ }^{14}$ establece que tanto el análisis de los roles y vulnerabilidades de la trata, así como las respuestas a este fenómeno deben tener en cuenta la perspectiva de género.

En este contexto adquieren especial virtualidad los estereotipos, pues condicionan la identificación de las víctimas de trata y los procedimientos de protección y tutela (FERNÁNDEZ, 2016) , acarreando consecuencias perjudiciales para los derechos de las mujeres $^{15}$.

El Informe de Greta sobre España del año $2018^{16}$, ha reflejado la preocupación de las Organizaciones no Gubernamentales por el impacto negativo de los estereotipos de género en la identificación de las víctimas que condicionan a los propios funcionarios encargados de la identificación que presuponen que las mujeres que son víctimas se comporten de cierta manera y, si no lo hacen, cuestionan su condición de víctimas.

\section{La situación en España}

España es un país de tránsito y destino de víctimas de trata de seres humanos ${ }^{17}$. E principal reto al que se enfrenta España, muy especialmente dada su condición de única frontera terrestre europea con el continente africano, es sin duda la importancia de identificación ágil y de diferenciación entre las personas que intentan acceder a Europa de manera irregular, las que se encuentran en necesidades de protección internacional y las que son víctimas de trata ${ }^{18}$.

intolerancia. Visita a España. Junio, 2013. Documento: A/HRC/23/56/Add.2. Párrafo 51:" El problema de los controles policiales de identidad de que son objeto grupos étnicos concretos, como las minorías, los romaníes y los inmigrantes, especialmente procedentes de África, Asia y Sudamérica, todavía está por resolver. De hecho, el uso de perfiles raciales por los agentes del orden sigue siendo un problema persistente y generalizado, que repercute negativamente en la relación entre la policía y la comunidad y en el disfrute de los derechos de las personas afectadas. El Anvario Estadístico del Ministerio del Interior revela un aumento del 23\% en las identificaciones en España entre 2010 y 2011. El Defensor del Pueblo, en su informe anual de 2011, señaló que había recibido un número elevado de denuncias por el uso generalizado de las identificaciones de extranjeros por parte de la policía". PARLAMENTO EUROPEO. Resolución del Parlamento Europeo, de 5 de julio de 2016, sobre la lucha contra el tráfico de seres humanos en las relaciones exteriores de la UE. La lucha contra la trata de seres humanos en las relaciones exteriores de la UE. Documento: 2015/2340(INI). Tendencias de la trata de seres humanos en el mundo. Párrafo 12.

${ }_{13}$ Artículo 1 Directiva 2011/26/CE.

${ }^{14}$ NACIONES UNIDAS. Comentario conjunto de Naciones Unidas a la Directiva de la Unión Europea. Un enfoque de Derechos Humanos. Madrid. 2011.p.22.

15 Sentencia del Tribunal Superior de Justicia de Canarias, sala de lo Social; sección 1, de fecha 2 de mayo de 2017. ROJ: STSJ ICAN 131/2017.

${ }^{16}$ SECRETARIAT OF THE COUNCIL OF EUROPE CONVENTION ON ACTION AGAINST TRAFFICKING IN HUMAN BEINGS (GRETA). Report concerning the implementation of the Council of Europe Convention on Action against Trafficking in Human Beings by Spain, second evaluation round. Strasourg. June 2018.p.35

17 MINISTERIO DE IGUALDAD. Plan integral de lucha contra la trata de seres humanos con fines de explotación sexual. Madrid, 2010. p. 14 .

${ }^{18}$ DEFENSOR DEL PUEBLO. Informe del Defensor del Pueblo del año 2015, p. 243. 
Según UNODC ${ }^{19}$, la mayoría de las víctimas de trata de seres humanos con fines de explotación sexual detectadas en Europa provienen de África, de las que el 18\% provienen de Nigeria y en concreto del Estado de Edo al suroeste de Nigeria. En el año 2006, Unesco establecía que el 92\% de las víctimas de trata de nacionalidad nigeriana provenían de este estado ${ }^{20}$.

En nuestro país en el año 2017, de un total de 366 mujeres identificadas como víctimas de trata de seres humanos, 212 tenían nacionalidad nigeriana ${ }^{21}$. De este modo, el porcentaje de víctimas mujeres nigerianas, en proporción con otras nacionalidades, es superior al 65\%. Esta tendencia que se consolida ya en el año 2016 de 323 mujeres víctimas de trata identificadas, 212 ostentaban nacionalidad nigeriana ${ }^{22}$.

En el caso español hemos de patentizar la existencia de déficits en la identificación de las víctimas (STORINI, 2007. NARAYAN, 2013) ${ }^{23}$. Situación que se hace, especialmente grave para las mujeres que quedan embarazadas en el tránsito o durante la explotación y sus hijos ${ }^{24}$.

Por lo que se refiere a la identificación, fue a partir del año 2014 cuando la Fiscalía General del Estado ${ }^{25}$ constató un aumento de llegadas de mujeres nigerianas con indicios de ser víctimas de trata de seres humanos que llegaban a las costas españolas acompañadas de bebés o niños de muy corta edad.

En un intento de tutela de los menores se impuso la realización de pruebas de ADN que constatase la existencia de vínculos biológicos entre éstos y las mujeres con las que viajaban. El Dictamen $5 / 2014^{26}$ analiza la protección de menores extranjeros que

19 UNDOC. Oficina de las Naciones Unidas para las Drogas y el Delito. Informe global sobre trata de seres humanos. Austria, 2012.p.37.

20 UNESCO, "Trata de seres humanos en Nigeria: principales causas y recomendaciones", Documento de trabajo No 14.2, Paris, 2006. p.16.

${ }^{21}$ FISCALÍA GENERAL DEL ESTADO. Memoria de actividad. Madrid, 2017.p.529.

${ }^{22}$ FISCALÍA GENERAL DEL ESTADO. Memoria de actividad. Madrid, 2016.p.475.

23 EUROPOL. Situation report. Trafficking in human beings in the EU. The Hague, 2016. Documento no: 765175.p. 24. PARLAMENTO EUROPEO. LOCHBIHLER, B. Comisión de Asuntos Exteriores. Subcomisión de Derechos Humanos. Proyecto de informe sobre la lucha contra el tráfico de seres humanos en las relaciones exteriores de la UE. Documento: 2015/2340(INI) .Párrafo 22.

${ }^{24}$ UNICEF. Guidelines on the protection of child victims of trafficking. New York. 2006. FUNDAMENTAL RIGHTS AGENCY. La tutela de menores privados de cuidados parentales: Manual para reforzar los sistemas de tutela para satisfacer las necesidades específicas de los menores que son víctimas de trata de seres humanos. Luxemburgo, 2015.P.32.

25 FISCALÍA GENERAL DEL ESTADO. Memoria de actividad. Madrid, 2014.

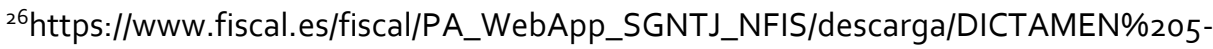

2014\%20sobre\%2oprotecci\%C3\%B3n\%2ode\%2omenores\%2oextranjeros\%2oque\%2oacceden\%2oirre gularmente\%2oal\%2oterritorio\%2oen\%2ocompa\%C3\%B1\%C3\%ADa\%2ode\%2opersonas\%2osin\%2ov $\%$ C3\%ADnculo\%2oacreditado\%2ode\%2oparentesco\%2oy-

o\%2oen\%2oriesgo\%2ode\%2ovictimizaci\%C3\%B3n?idFile=2b76c647-1b22-4361-ado5-33171deg683a .p. 25 . 
acceden irregularmente al territorio en compañía de personas sin vínculo acreditado de parentesco y/o en riesgo de victimización.

El rechazo injustificado de la prueba genética o la inexistencia acreditada de vínculo de filiación podrán fundar la solicitud de medidas judiciales de protección del art. 158 del Código Civil ${ }^{27}$ (prohibición de abandono del centro, obligación de comunicar cambios de residencia....) e incluso, la separación del niño con asunción de su tutela por parte de la Entidad Pública de protección, cuando aquel rechazo o la ausencia de vínculo, unidos al resto de circunstancias, revelen insuficiente garantía de la necesaria asistencia material o moral del niño.

Debe destacarse, el criterio establecido para los supuestos en que no estén acreditados los vínculos de filiación, o se sospeche de su realidad. Así, en estos supuestos ${ }^{28}$ : "El rechazo a la protección prevista en el art. 59 de la Ley de Extranjería ${ }^{29}$ por parte de la madre o mujer que acompaña al niño, no equivale sin más a la inexistencia de sospechas sobre su sumisión a los designios de personas, grupos u organizaciones criminales y por ende, de riesgos añadidos de diferente gravedad para el niño a su cargo".

Cuando se hubieran acreditado vínculos de filiación, los riesgos serán ponderados en atención a las circunstancias concurrentes en cada caso, debidamente justificadas que, de nuevo se vincula a la respuesta de la mujer al período de restablecimiento y reflexión: "(...) Cuando se hubiera apreciado la posible victimización de la madre o adulto de referencia por trata de personas al sólo efecto del art. 59 de la Ley de Extranjería, sin que concurrieran elementos suficientes para iniciar o continuar los trámites del proceso penal por delito, los riesgos para el niño deben considerarse muy importantes a fin de analizar y elegir las medidas de protección que sean precisas y que no afectarán a la madre".

Las cifras de períodos de restablecimiento y reflexión concedidos en nuestro país, nos proporcionan una pauta interpretativa. Así3 ${ }^{\circ}$, durante el año 2013 se concedieron 99 períodos de restablecimiento y reflexión. En el año 2014 se otorgaron un toral de 62, en 2015 fueron 95 y en 2016 la cifra de períodos de restablecimiento y reflexión fue de 81 .

\footnotetext{
${ }^{27}$ Real Decreto de 24 de julio de 1889 por el que se publica el Código Civil. «Gaceta de Madrid» de 25/07/1889.

${ }^{28} \mathrm{https} / / /$ www.fiscal.es/fiscal/PA_WebApp_SGNTJ_NFIS/descarga/DICTAMEN\%205-

2014\%2osobre\%2oprotecci\%C3\%B3n\%2ode\%2omenores\%2oextranjeros\%2oque\%2oacceden $\% 2$ oirre gularmente\%2oal\%2oterritorio\%2oen\%2ocompa\%C3\%B1\%C3\%ADa\%2ode\%2opersonas\%2osin\%20v $\%$ C3\%ADnculo\%2oacreditado\%2ode\%2oparentesco\%2oy-

o\%2oen\%2oriesgo\%2ode\%2ovictimizaci\%C3\%B3n?idFile=2b76c647-1b22-4361-ado5-33171deg683a .p. 25 .

${ }^{29}$ Ley Orgánica 4/2000, de 11 de enero, sobre derechos y libertades de los extranjeros en España y su integración social. BOE de 12/01/2000.

$3^{\circ}$ SECRETARIAT OF THE COUNCIL OF EUROPE CONVENTION ON ACTION AGAINST TRAFFICKING IN HUMAN BEINGS (GRETA). Report concerning the implementation of the Council of Europe Convention on Action against Trafficking in Human Beings by Spain, second evaluation round. Strasourg. June 2018.p.46.
} 


\section{La tutela de los menores}

La Ley Orgánica de Protección Jurídica del Menor ${ }^{31}$ y la Ley de modificación del sistema de protección a la infancia y a la adolescencia ${ }^{32}$ articulan las actuaciones en situaciones de desprotección social del menor, por lo que ahora nos interesa, entorno a las figuras de la declaración de riesgo y la declaración de desamparo.

\subsection{El interés superior del menor}

El interés superior del menor constituye el principal criterio interpretativo en materia de protección a menores y especialmente si fueran víctimas de trata33. Éste tiene un contenido doble (ARRIOLA, 2013): por un lado, la obligación de las instituciones de adoptar sus decisiones con el objetivo de satisfacer el interés del menor. Por otro, el de prevalencia del mismo ante eventuales conflictos de intereses.

De conformidad, con la Ley Orgánica de Protección del Menor y la Ley de modificación del sistema de protección a la infancia y a la adolescencia, se encontrarán en situación de riesgo ${ }^{34}$ aquella en la que, a causa de circunstancias, carencias o conflictos familiares, sociales o educativos, el menor se vea perjudicado en su desarrollo personal, familiar, social o educativo, en su bienestar o en sus derechos de forma que, sin alcanzar la entidad, intensidad o persistencia que fundamentarían su declaración de situación de desamparo.

Tal y como establece el Protocolo de Menores Extranjeros no Acompañados35, cuando se detecte un menor extranjero no acompañado que presente indicios de ser víctima de trata se le derivará a un "centro de protección de menores o, si así procede en atención a las exigencias de protección integral del menor, en centros de acogida de una asociación, fundación u organización no gubernamental sin ánimo de lucro que disponga de los medios necesarios que garanticen su seguridad, recuperación física y psicológica, y la asistencia integral que requiera".

El Protocolo Marco de Protección de las Víctimas de Seres Humanos establece que los menores deben ser derivados a recursos especializados dotados y capacitados para satisfacer las específicas necesidades que presentan éstos menores ${ }^{36}$. La

\footnotetext{
$3^{31}$ Ley Orgánica 1/1996, de 15 de enero, de Protección Jurídica del Menor, de modificación parcial del Código Civil y de la Ley de Enjuiciamiento Civil. BOE de 17/01/1996.

$3^{2}$ Ley $26 / 2015$, de 28 de julio, de modificación del sistema de protección a la infancia y a la adolescencia. BOE de 29/07/2015.

33 PARLAMENTO EUROPEO. Resolución del Parlamento Europeo, de 5 de julio de 2016, sobre la lucha contra el tráfico de seres humanos en las relaciones exteriores de la UE. La lucha contra la trata de seres humanos en las relaciones exteriores de la UE. Documento: 2015/2340(INI). Diferentes formas de explotación. Párrafo 35: "Pide que se refuercen los regímenes nacionales de tutela de los menores en Europa como parte integrante de la estrategia de la Unión de lucha contra la trata, que reconoce el papel fundamental que desempeñan los tutores en la protección de los menores contra toda forma de perjuicios".

${ }^{34}$ Artículo 17 párrafo 1.

35 Protocolo Marco sobre determinadas actuaciones en relación con los Menores Extranjeros No Acompañados, capítulo III apartado tercero.

${ }^{36}$ Protocolo Marco de Protección de las Víctimas de Trata de Seres Humanos, apartado XIV.A.
} 
declaración de riesgo puede constituir una solución adecuada siempre que se adopte con fundamento el interés superior del menor.

En ese sentido, la protección de las víctimas, madres e hijos y de sus vínculos con una comprensión integral del fenómeno y de las prácticas culturales de las víctimas es fundamental para que, por un lado, no se produzca una revictimización de los menores $y$, por otro, se garantice el derecho fundamental de los mismos a vivir con su madre ${ }^{37}$.

\subsection{La situación de desamparo}

El artículo 18 de la ya meritada Ley de Protección de Menor, establece que:" la situación de desamparo se produce a causa del incumplimiento o del imposible o inadecuado ejercicio de los deberes de protección establecidos por las leyes para la guarda de los menores, cuando éstos queden privados de la necesaria asistencia moral o material".

En particular se entenderá que existe situación de desamparo cuando se dé alguna o algunas de las siguientes circunstancias con la suficiente gravedad que, valoradas y ponderadas conforme a los principios de necesidad y proporcionalidad, supongan una amenaza para la integridad física o mental del menor ${ }^{38}: "$ f ) La inducción a la mendicidad, delincuencia o prostitución, o cualquier otra explotación del menor de similar naturaleza o gravedad".

Ahora bien, será preciso, adicionalmente, para que la tutela de los mismos sea adecuada a su situación, que sean identificados como víctimas de trata.

\subsection{Declaración de riesgo y situación de desamparo}

Sobre la delimitación con la situación de riesgo en el caso de víctimas de trata es destacable la Sentencia de la Audiencia Provincial de Barcelona de fecha 13 de febrero de $2017^{39}$ que resuelve un recurso de apelación interpuesto contra la sentencia de primera instancia que desestimó su oposición a la resolución de la DGAIA de fecha 10 febrero 2015 que ratifico el desamparo de sus dos hijas Carolina y Gabriela además de mantener la medida de ingreso en Centro. Solicita la actora en su recurso que se declare que la situación de las menores es de riesgo y no de desamparo, que la Sra. Vanesa es víctima de trata de seres humanos y la DGAIA no actuó conforme establece la normativa para garantizar sus derechos y los de su familia. Solicita que dado que las menores han estado 9 meses en el momento de la demanda, en un centro conforme al art. 35 LO 4/2000, la DGAIA solicite autorización de residencia para las dos niñas, con efectos retroactivos.

${ }^{37}$ ASAMBLEA GENERAL DE NACIONES UNIDAS. Convención de Derechos del Niño. 20 de noviembre de 1989. Artículo 9.

${ }^{38}$ Artículo 18 párrafo 2 de la Ley Orgánica 1/1996, de 15 de enero, de Protección Jurídica del Menor

39 Sentencia de la Audiencia Provincial de Barcelona de fecha 13 de febrero de 2017, Roj: SAP B 938/2017.

IQUAL. REVISTA DE GÉNERO E IGUALDAD, 2020, 3, 94-107 
La recurrente, llegó a España y desde un inicio Cruz Roja Española consideró que era víctima de trata de seres humanos y la Policía la identificó como tal. Por ello se le proporcionó la asistencia legalmente prevista para su situación.

Efectivamente, en un principio, tal y como consta en distintos expedientes de Cruz Roja, del Centro Els Estels, del EAIA, de los servicios sociales, Vanesa tuvo una actitud poco clara, con contradicciones. Inicialmente, negó su maternidad respecto de una de sus hijas, aduciendo que era hija de otra mujer con al que había viajado. El único objetivo era ayudar a su compañera de viaje a evitar la deportación.

La administración consideró que Vanesa no tuvo en cuenta las necesidades de sus hijas- Así, consta en el expediente:" los sentimientos y temores que deben haber padecido las niñas en un viaje de 405 meses a través de varios países y viaje en patera hasta España, mostrando con ello una importante falta de empatía hacia las niñas sin que hasta la fecha sepa como ayudar a las niñas a superar sus temores. Tampoco aprecia los sentimientos de las niñas cuyo cuidado delegaba en un matrimonio para que las cuidara a cambio del precio de 500 euros, cuando ella no podía atenderlas personalmente".

Nuestra protagonista, sufría las consecuencias de ser víctima de trata, era presa de un sentimiento de miedo que no favoreció la comprensión de su situación y la de las niñas.

Por ello, la Dirección General de Atención a la Infancia y la Adolescencia, en adelante DGAIA, encargada de velar por la protección de las menores, consideró que la actitud materna no favorecía el retorno de las menores con ella. La falta de habilidades para ayudarles a superar los temores que tuvieron que vivir, fueron determinantes para que la DGAIA declarara la situación de desamparo de las menores.

Pese a que según consta en las actuaciones durante las visitas que tuvieron lugar en un primer momento, no mostraba un vínculo cercano con sus hijas, dedicando la madre la mayor parte del tiempo a mostrar su enojo a los profesionales sobre signos externos de las niñas, quejándose de la forma de vestir y de peinarlas, sin que interactuara con las niñas ni se mostrara cariñosa con ellas. Con posterioridad, Vanesa fue cumpliendo los objetivos y mejoró su situación en diversos ámbitos. En ese sentido, los informes de seguimiento fueron constatando que se observaba el cariño entre madre e hijas.

Es sencillo deducir del tenor literal de los hechos probados así como de la transcripción de determinados aspectos del procedimiento administrativo la situación y los prejuicios que vivieron Vanesa y sus hijas. En ese sentido, se hace necesaria una adecuada formación de cuantos agentes tienen o pueden tener algún tipo de relación con víctimas de trata.

\subsection{El fracaso del sistema}


La Sentencia del Tribunal Supremo de fecha 2 de marzo de $2017^{40}$, expone en sus hechos probados, las repercusiones que acarrea el fracaso del sistema por la falta de identificación de las víctimas.

Graciela fue captada por Cornelio en Nigeria. Éste lo hizo abusando de su situación de necesidad, debido a una situación de gran precariedad económica, y engañándola sobre el trabajo que desarrollaría en España. Graciela viajó de Nigeria a Marruecos y en éste país quedó embarazada de su hijo Salvador. Diez días más tarde del nacimiento de su hijo, Graciela llegó a España en patera.

Graciela estuvo ejerciendo la prostitución desde su llegada a España, en diciembre de $\mathbf{2 . 0 0 0 , ~ h a s t a ~ e l ~ a n ̃ o ~} \mathbf{2 . 0 0 4}$, en que la policía la detuvo mientras se encontraba

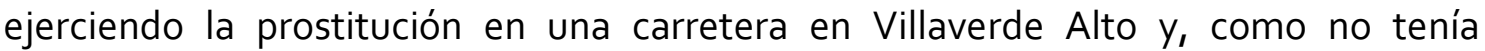
documentación, fue expulsada de España, en dicho año, volviendo así a Nigeria.

Desde diciembre del año 2000 hasta la expulsión de Graciela en el año 2004, esta última y su hijo, Salvador, estuvieron residiendo en la vivienda de Cornelio. Tras la expulsión de su madre, el pequeño Salvador permaneció con Cornelio. Así lo aceptó Graciela que debido a su desconocimiento del ordenamiento así como del contexto español, creyó a Cornelio cuando le aseguró que él haría gestiones para intentar que permaneciera en España y que no la expulsaran.

Con ocasión de la expulsión de Graciela, el acusado comenzó a ocultar la verdadera filiación del hijo de Graciela y a hacerse pasar por sus padres en el colegio al que acudía y ante los organismos oficiales, llegando incluso a obtener un falso certificado de nacimiento del menor, supuestamente expedido en Nigeria el 19 de julio de 2.007 , en el que se hacía constar que había nacido en dicho país y que era su hijo.

En el año 2.007, el acusado contactó de nuevo con Graciela en Nigeria y le dijo que iba a traerla de nuevo a España para que pudiera recuperar a su hijo, aunque su verdadera intención era lucrarse con un nuevo ejercicio de la prostitución por parte de Graciela. Graciela inició un nuevo viaje en dicho año, que fue también costeado por el acusado, llegando a España en patera en el mes de enero del año 2.008, viajando a continuación sola desde Algeciras hasta Madrid con el dinero que el acusado le había dado para que realizase dicho viaje.

Cuando Graciela llegó a Madrid, en ese mismo mes de enero del año 2.008, acudió a la casa en la que había vivido con su hijo y pidió que le entregara a su hijo, diciéndole la acusada que tenía que trabajar otra vez como prostituta para pagar la deuda derivada del hecho de haberla traído por segunda vez a España y del hecho de haber estado cuidando y manteniendo a su hijo, Salvador., desde que fue expulsada de España.

Graciela se negó a prostituirse de nuevo y suplicó a los acusados que le entregaran a su hijo, a lo que ambos se negaron, diciendo que les debía 40.000 euros, tanto por

\footnotetext{
$4^{0}$ Las historias que se narran son, sustancialmente, hechos probados en procedimientos judiciales sustanciados con todas las garantías en España. Por ello, su certeza es indiscutible. El caso concreto de Graciela se analiza en la Sentencia del Tribunal Supremo de fecha 2 de marzo de 2017.Roj: STS $735 / 2017$.
} 
haberla traído a España como por la manutención del menor durante todo el tiempo que este último había permanecido con ellos, añadiendo que hasta que no pagara esa cantidad no le harían entrega de su hijo.

Entre tanto la Comisión de Tutela del Menor de la Comunidad de Madrid se dictó resolución de 10 de julio de 2.007 por la que se declaró la situación de desamparo del hijo de Graciela asumiéndose la tutela del menor por la Comunidad de Madrid, a fin de que fuese ejercida en acogimiento residencial, de tal manera que, el día 16 de abril de 2.008, ingresó en un centro de acogida de la Comunidad de Madrid.

Graciela tuvo conocimiento en el mismo año 2.008 de que su hijo había sido ingresado en un centro de acogida de la Comunidad de Madrid, pero los acusados se negaron a informar a Graciela del concreto centro en el que el menor se encontraba y se hicieron pasar por los padres de Salvador, en todo momento, ante la Comunidad de Madrid, ocultando la existencia de una madre biológica del menor y la presencia de esta en España.

Pese a las continuas peticiones que Graciela vino realizando a los acusados, desde que llegó por segunda a España en enero de 2.008, para que le hicieran entrega de su hijo, estos se negaron, diciéndole que no lo harían hasta que ella pagase lo que debía, de tal manera que obstaculizaron toda posibilidad de contacto de Graciela con su hijo, manteniendo el control de este último, por la vía de situación de legalidad en España en la que Graciela se encontraba y, por tanto, de la limitada capacidad de actuación de esta última.

Tal situación se mantuvo hasta que, en fecha 22 de enero de 2.013, Graciela decidió acudir a la policía y denunciar los hechos, con la finalidad de poder recuperar a su hijo. El día 22 de enero de 2.014, la Comisión de Tutela del Menor de la Comunidad de Madrid dictó resolución acordando promover judicialmente el acogimiento familiar permanente del hijo de Graciela por una familia seleccionada al efecto por la referida Entidad Pública.

\section{Conclusiones}

Este fenómeno requiere una respuesta interdisciplinaria y coordinada que involucre a todos los actores de la sociedad tanto en el contexto nacional como regional e internacional. Así, como en los países de origen como a los de tránsito y destino.

Es esencial que las estrategias destinadas a prevenir y reprimir la trata de seres humanos se centren tanto en los factores que contribuyen a la misma como en las causas y circunstancias subyacentes. Así, en ningún caso, será viable para acabar con esta execrable realidad la adopción de una perspectiva exclusivamente penal.

La trata de seres humanos es un proceso dinámico cuyos parámetros cambian constantemente respondiendo a las distintas condiciones económicas, sociales y políticas. Aunque pueden diferir los objetivos por los cuales se lleva a cabo la trata de seres humanos, el modo en que se realiza y los países desde los cuales y hacia los cuales se realiza el delito de trata se mantienen constantes. 
Para la consideración de una víctima de trata de seres humanos como tal, el Legislador español ha establecido dos pasos sucesivos e imprescindibles para que se produzca la consideración de una persona como víctima de trata. Son por un lado, la detección y por otro, la identificación de la misma.

Es esencial identificar a las víctimas pues no sólo constituye un derecho de las mismas sino además es una obligación estatal.

Las mujeres víctimas de trata, casi en la generalidad, son trasladadas por las redes, bien dentro de un mismo país o a través de ellos lo que en ocasiones significa que pierden el contacto con sus hijos y estos se instrumentalizan para coaccionarlas.

Desde ese prisma, se hace precisa la comunicación entre los sistemas de protección a las víctimas de trata y de protección a la infancia.

En esa línea sería deseable la articulación en la Unión de un sistema que permitiera dar cobertura a las situaciones en que las víctimas y sus hijos han sido separadas y se encuentran en distintos países.

Asimismo, es fundamental que se incorporen adecuadamente las preceptivas perspectivas de género y de derechos humanos pues pese a que han sido incorporadas a la retórica gubernamental no tienen una adecuada efectividad en la práctica.

\section{Bibliografía}

DEFENSOR DEL PUEBLO. Informe. Madrid. 2015.

EUROPEAN PARLIAMENT, FERNÁNDEZ RODRÍGUEZ DE LIÉVANA, G. and WAISMAN, V. Assesment of the implementation of the directive 2011/36/eu from a gender perspective in Spain. 2016.

EUROPOL. Situation report. Trafficking in human beings in the EU. The Hague, 2016. Documento no: 765175 .

FISCALÍA GENERAL DEL ESTADO. Memoria de actividad. Madrid, 2016.

FISCALÍA GENERAL DEL ESTADO. Memoria de actividad. Madrid, 2014.

FRONTEX. Situational Overview on Trafficking in Human Beings. Varsovia, 2011.

FRONTEX. Annual Risk Analysis. Varsovia, 2012.

FUNDAMENTAL RIGHTS AGENCY. La tutela de menores privados de cuidados parentales: Manual para reforzar los sistemas de tutela para satisfacer las necesidades específicas de los menores que son víctimas de trata de seres humanos. Luxemburgo, 2015.

MINISTERIO DE IGUALDAD. Plan integral de lucha contra la trata de seres humanos con fines de explotación sexual. Madrid, 2010.

NACIONES UNIDAS. Comentario conjunto de Naciones Unidas a la Directiva de la Unión Europea. Un enfoque de Derechos Humanos. Madrid. 2011.

PARLAMENTO EUROPEO. Resolución del Parlamento Europeo, de 5 de julio de 2016, sobre la lucha contra el tráfico de seres humanos en las relaciones exteriores de la UE. La lucha contra la trata de seres humanos en las relaciones 
exteriores de la UE. Documento $\mathrm{n}^{\circ}$ 2015/2340(INI). Derechos de las víctimas, incluido el derecho de recurso.

PARLAMENTO EUROPEO. LOCHBIHLER, B. Comisión de Asuntos Exteriores. Subcomisión de Derechos Humanos. Proyecto de informe sobre la lucha contra el tráfico de seres humanos en las relaciones exteriores de la UE. Documento: 2015/2340(INI).

SECRETARIAT OF THE COUNCIL OF EUROPE CONVENTION ON ACTION AGAINST TRAFFICKING IN HUMAN BEINGS (GRETA). Report concerning the implementation of the Council of Europe Convention on Action against Trafficking in Human Beings by Spain, second evaluation round. Strasourg. June 2018.

UNDOC. Oficina de las Naciones Unidas para las Drogas y el Delito. Informe global sobre trata de seres humanos. Austria, 2012.

UNESCO, "Trata de seres humanos en Nigeria: principales causas y recomendaciones", Documento de trabajo No 14.2, Paris, 2006.

UNICEF. Guidelines on the protection of child victims of trafficking. New York. 2006.

WOMENS LINK. Madres en las redes de trata: derechos robados. Informe n8. Madrid, 2017.

\section{Anexo jurisprudencial}

Tribunal Europeo de Derechos Humanos. Asunto Rantsev vs Chipre y Rusia, sentencia de fecha 7 de enero de 2010.

Sentencia del Tribunal Supremo de fecha 2 de marzo de 2017.Roj: STS 735/2017.

Sentencia del Tribunal Superior de Justicia de Canarias, sala de lo Social; sección 1, de fecha 2 de mayo de 2017. ROJ: STSJ ICAN 131/2017.

Sentencia de la Audiencia Provincial de Barcelona de fecha 13 de febrero de 2017, Roj: SAP B 938/2017.

Cómo referenciar este artículo/How to reference this article:

García Sedano, T. (2020). Víctimas de trata de seres humanos, madres de seres humanos: protegiendo derechos. iQUAL. Revista de Género e Igualdad, 3, 94-107, doi: 10.6018/iqual.395931

García Sedano, T. (2020). Víctimas de trata de seres humanos, madres de seres humanos: protegiendo derechos. [Victims of trafficking in human beings, mothers of human beings: protecting rights]. iQUAL. Revista de Género e Igualdad, 3, 94-107, doi: 10.6018/iqual.395931 